\title{
Delay to invasive investigation and revascularisation for coronary heart disease in South West Thames region: a two tier system?
}

\author{
Michael Marber, Callum MacRae, Michael Joy
}

\begin{abstract}
Objectives - To assess the accessibility of invasive investigation and revascularisation procedures in the management of coronary heart disease in a defined population in the South West Thames region over 10 years, and to audit the performance of both the NHS and the private sector.
\end{abstract}

Design-Analysis of all patient referrals to the regional cardiothoracic centres for coronary heart disease during 1979-88.

Setting-North West Surrey District Health Authority, which had a mean catchment population of 205000 during the study period. The health district is one of the 13 in the South West Thames region.

Patients -823 patients aged 34-80 years with suspected coronary heart disease, 204 of whom were referred for private investigation and 619 were referred within the NHS. The NHS referrals were mainly to St Thomas's Hospital during 1979-83 and to St George's Hospital during 1984-8.

Main outcome measures-Difference in time to investigation and intervention between the NHS and the private patients.

Results-After some variation in earlier years the mean (SD, range) waiting times from referral to cardiac catheterisation and then revascularisation increased progressively in NHS patients, to 115.8 $(126 \cdot 5,22-482)$ days and $305.9(164.4,22-620)$ days respectively in 1988 . There was no significant change over the 10 years in waiting times within the private sector, with a mean of $17.2(18.2,1-62)$ days to angiography and $22.8(14.5,2-152)$ days to surgery. Fifteen people on the NHS waiting list died of probable cardiac causes. No people on the private waiting list died.

Conclusions-The performance of the NHS system in South West Thames region in response to emergency referral is adequate. The waiting time to routine investigation and revascularisation is prolonged and seems to be worsening despite increased investigative and surgical activity by the regional centre. The delays may subject NHS patients to unnecessary risk, which is not shared by private patients.

St Peter's Hospital,

Chertsey, Surrey KT16 0PZ Michael Marber, MRCP, registrar in general medicine Callum MacRae, MRCP, registrar in general medicine Michael Joy, FRCP, consultant cardiologist

Correspondence to: Dr Joy.

BMY 1991;302:1189-91

\section{Introduction}

Coronary heart disease accounts for about two fifths of all deaths in England and Wales. ${ }^{1}$ There is evidence that coronary bypass surgery can benefit survival ${ }^{2}{ }^{3}$ as well as reduce symptoms and improve quality of life, ${ }^{4}$ especially if waiting times are short. Patients with coronary heart disease have a prognosis related to coronary anatomy and left ventricular function. Those with severe disease often have a prognosis worse than that associated with some common malignancies. Despite this, coronary heart disease does not seem to engender the same sense of urgency as that accorded to cancer, and the provision of services in cardiology in the United Kingdom is still relatively poor. ${ }^{6}$ We studied the effect of this underprovision by auditing waiting times experienced by patients in North West Surrey District Health Authority for invasive investigation and revascularisation of the myocardium between 1979 and 1988 inclusive.

\section{Methods}

In January 1979 a database was established in our hospital to record details of all patients referred to regional centres for invasive cardiological investigation and intervention. ${ }^{7}$ When a patient with suspected coronary artery disease was referred for angiography a copy of the referral letter was set aside and used to record a new patient entry into a continuing database. Patients with one or more problems in addition to coronary artery disease (for example, valvular heart disease, arrhythmia, and pacing) were also included in this analysis. Emergency inpatient referrals for patients with unstable symptoms could be made without a referral letter; these patients were identified retrospectively by recording the transfers to cardiac centres appearing in the cardiology ward discharge records. Once a patient was entered in the database his or her entry was updated by using the discharge summaries supplied by the regional centre after cardiac catheterisation and revascularisation. The referral policy at the hospital is such that all referrals to regional cardiac units are made by the cardiology team. Private patients were referred by one of us $(\mathrm{MJ})$ and the initial referral letters copied and kept in a separate file. Once every calendar year this file together with the patients' notes were used to update the database by adding the referrals made to the private sector.

Information recorded included medical history; diagnosis; severity of symptoms (New York Heart Association classification); drugs taken; and dates of referral for investigation, angiography, and surgery or angioplasty. Angiographic findings with respect to number of vessels stenosed and left ventricular function as reported by the operator were also recorded.

The entries in the database were regularly reviewed to identify patients who seemed to have waited an unacceptable length of time for investigation or surgery and the regional centre then contacted. When a patient on the waiting list died outside hospital the cause of death was established as cardiac or non-cardiac on the basis of findings at postmortem examination and the circumstances of the death. People who had died were also identified by failure to attend hospital.

For the purpose of the study patients requiring emergency inpatient referral were considered as a separate group and referred to as having unstable angina. Patients referred with initially stable symptoms who subsequently deteriorate and require hospital 
admission and emergency investigation or revascularisation were classified according to their original group.

The mean catchment population over the 10 year audit period was 205000 . Statistical analysis was carried out using standard methods for estimating means, standard deviations, and confidence intervals. ${ }^{84}$

\section{Results}

Over the 10 years from 1979 to 1988,823 patients were referred for angiographic assessment for coronary artery disease. In all, $619(75 \cdot 2 \%)$ were referred within the NHS and $204(24 \cdot 8 \%)$ to the private sector. Eleven patients referred for angiography were never investigated (six died and five refused catheterisation or were lost to follow up, or both). Thirty one patients had suspected coronary artery disease in addition to other cardiac disease; 32 had normal coronary arteries.

During the first five years NHS patients were referred mainly to St Thomas's Hospital $(n=189)$ and during the second five years almost exclusively to $\mathrm{St}$ George's Hospital $(n=430)$. The private patients were referred to consultants at the corresponding referral centre.

A total of 495 patients $(60 \cdot 1 \%)$ subsequently underwent revascularisation by coronary artery bypass grafting and $40(4 \cdot 9 \%)$ by percutaneous transluminal coronary angioplasty. In addition, 16 patients underwent bypass grafting during the course of valvular surgery.

NHS and private patients over the 10 years were similar in respect to mean (SD) age $(57 \cdot 2(6 \cdot 3)$ years and $57 \cdot 5(7 \cdot 2)$ years respectively), sex $(101(16 \cdot 3 \%)$ and

TABLE I-Percentage (number) of NHS and private patients with various forms of ischaemic heart disease

\begin{tabular}{lcc}
\hline & \multicolumn{2}{c}{ Proportion of patients } \\
\cline { 2 - 3 } Type of disease & NHS & Private \\
\hline Single vessel & $21 \cdot 1(126)$ & $25 \cdot 0(46)$ \\
Double vessel & $27 \cdot 3(163)$ & $23 \cdot 9(44)$ \\
Triple vessel & $48 \cdot 2(287)$ & $47 \cdot 3(87)$ \\
Left main stem & $3 \cdot 3(20)$ & $3 \cdot 8(7)$ \\
\hline
\end{tabular}

TABLE II -Number of NHS and private patients with angina referred in North West Surrey District Health Authority each year. NHS patients were subdivided according to type of angina

\begin{tabular}{lccc}
\hline & \multicolumn{2}{c}{ NHS patients } & \\
\cline { 2 - 3 } Year of referral & Stable angina & Unstable angina & Private patients \\
\hline 1979 & 12 & 2 & 3 \\
1980 & 15 & 6 & 8 \\
1981 & 25 & 10 & 10 \\
1982 & 49 & 12 & 22 \\
1983 & 49 & 9 & 25 \\
1984 & 42 & 12 & 10 \\
1985 & 43 & 11 & 23 \\
1986 & 63 & 20 & 24 \\
1987 & 93 & 17 & $35^{\star}$ \\
1988 & 104 & 25 & $44^{\star}$ \\
\hline Total & 495 & 124 & 204 \\
\hline
\end{tabular}

*One patient had unstable angina.

TABLE III-Mean (SD) number of days to angiography for NHS and private patients with suspected coronary artery disease with stable symptoms

\begin{tabular}{lccccc}
\hline $\begin{array}{l}\text { Year of } \\
\text { referral }\end{array}$ & NHS patients & Private patients & Mean (SD) difference & $\begin{array}{c}\text { Degrees of } \\
\text { freedom }\end{array}$ & 95\% Confidence interval \\
\hline 1979 & $75 \cdot 2(260 \cdot 5)$ & $9 \cdot 0(0)$ & $66 \cdot 2(82 \cdot 3)$ & 13 & $244 \cdot 0$ to $-111 \cdot 6$ \\
1980 & $113 \cdot 4(143 \cdot 3)$ & $22 \cdot 6(15 \cdot 6)$ & $90 \cdot 8(51 \cdot 4)$ & 21 & $197 \cdot 8$ to $-16 \cdot 1$ \\
1981 & $76 \cdot 7(78 \cdot 0)$ & $18 \cdot 2(13 \cdot 0)$ & $58 \cdot 5(25 \cdot 0)$ & 33 & $109 \cdot 4$ to $7 \cdot 6$ \\
1982 & $72 \cdot 3(126 \cdot 7)$ & $21 \cdot 5(32 \cdot 4)$ & $50 \cdot 8(27 \cdot 5)$ & 69 & $105 \cdot 7$ to $4 \cdot 1$ \\
1983 & $89 \cdot 6(98 \cdot 7)$ & $22 \cdot 1(31 \cdot 5)$ & $67 \cdot 5(20 \cdot 3)$ & 72 & $106 \cdot 7$ to $28 \cdot 3$ \\
1984 & $68 \cdot 2(44 \cdot 1)$ & $17 \cdot 8(42 \cdot 4)$ & $50 \cdot 4(15 \cdot 4)$ & 50 & $81 \cdot 9$ to $19 \cdot 5$ \\
1985 & $45 \cdot 8(58 \cdot 4)$ & $12 \cdot 8(20 \cdot 1)$ & $33 \cdot 0(12 \cdot 6)$ & 64 & $58 \cdot 2$ to $7 \cdot 8$ \\
1986 & $56 \cdot 6(59 \cdot 5)$ & $14 \cdot 9(18 \cdot 6)$ & $41 \cdot 7(12 \cdot 4)$ & 85 & $66 \cdot 4$ to 17 \\
1987 & $87 \cdot 0(69 \cdot 4)$ & $17 \cdot 8(15 \cdot 4)$ & $69 \cdot 2(11 \cdot 8)$ & 126 & $92 \cdot 6$ to $45 \cdot 8$ \\
1988 & $115 \cdot 8(126 \cdot 5)$ & $14 \cdot 3(25 \cdot 8)$ & $101 \cdot 5(19 \cdot 8)$ & 146 & $140 \cdot 6$ to $62 \cdot 4$ \\
\hline
\end{tabular}

$31(15 \cdot 2 \%)$ respectively were women), and overall pattern of diseased vessels (table I).

Table II gives the numbers of NHS patients referred for coronary angiography with stable angina and those referred with unstable angina and the number of patients referred to the private sector for coronary angiography. Over the 10 years there was a proportional increase in both private and NHS referrals.

Table III gives the mean waiting times to coronary angiography for private and NHS patients and the differences between the times with their respective $95 \%$ confidence intervals. Between 1984 and 1988, the point at which patients started to be referred to St George's Hospital, the mean (SD, range) time to cardiac catheterisation increased significantly from $68 \cdot 2(44 \cdot 1,23-153)$ days to $115 \cdot 8(126 \cdot 5,22-482)$ days The difference between these means was 47.6 days (95\% confidence interval $8 \cdot 0$ to $87 \cdot 2$ days $)(t=2 \cdot 4, \mathrm{df}=$ $144,0.02>\mathrm{p}>0.01$ ).

Over the 10 years in the private sector mean waiting time to angiography was $17 \cdot 2(18 \cdot 2,1-62)$ days. Table IV shows the waiting times to emergency angiography over the study period and relates to the NHS patients alone. Only two patients were referred privately for emergency investigation.

Table $\mathrm{V}$ gives the waiting times from coronary angiography to surgery. Four NHS patients referred in 1987 and 10 referred in 1988 were still awaiting surgery on 1 September 1990. The 1987 and 1988 data for NHS patients are therefore biased and understate the mean waiting times. Values were calculated as if waiting patients had been operated on on 1 September 1990 . The waiting time from investigation to surgery for NHS patients rose significantly from $107 \cdot 9(82.9,12$ 240) days in 1984 to $305 \cdot 9(164 \cdot 4,22-661)$ days in 1988 The difference between the means was 198 days $(95 \%$ confidence interval $118 \cdot 4$ to 227.6 days $)(t=4 \cdot 9, \mathrm{df}=$ $89, \mathrm{p}<0.0001)$. Over the 10 years in the private sector the comparable waiting times remained little changed with a mean of $22 \cdot 8(14 \cdot 5,2-152)$ days.

Six people on the NHS waiting list for angiography died suddenly, probably of cardiac causes after 79.5 $(59 \cdot 5,28-180)$ days and nine on the NHS waiting list for surgery died after $164 \cdot 0(134 \cdot 4,28-400)$ days. This death rate represents $2 \cdot 4 \%$ of the 619 patients referred for coronary angiography at the regional centre. Four people died of non-cardiac causes. Nobody on the private waiting lists died.

\section{Discussion}

Our data show that the provision of routine invasive investigation and surgical revascularisation of the myocardium by the South West Thames regional cardiac centre has become worse. This was despite an increase over the past five years in coronary angiographic and surgical procedures of $24.5 \%$ and $30 \%$ respectively (C Pumphrey, personal communication). In contrast the performance with regard to emergency investigation was reasonably satisfactory, although a mean wait of four days may be too long for patients with unstable angina in whom medical treatment has failed. The private sector has experienced no such difficulties or delays. The number of patients referred in each year except 1984 and 1985 has increased both in the private and NHS sectors in parallel fashion, although the incidence of coronary artery disease is probably declining in the United Kingdom. ' Reasons for the increased uptake of these procedures are likely to include consensus among physicians, general practitioners, and patients on the benefits of aggressive management. ${ }^{10}$

For best practice there should be no appreciable delay once a patient has been referred for coronary angiography. Preliminary risk stratification will have 
TABLE IV-Mean (SD) number of days to emergency angiography in NHS patients with suspected or known coronary artery disease

\begin{tabular}{lc}
\hline Year of referral & No of days \\
\hline 1979 & $0(0)^{\star}$ \\
1980 & $7 \cdot 4(17 \cdot 6)$ \\
1981 & $9 \cdot 9(18 \cdot 5)$ \\
1982 & $6 \cdot 3(13 \cdot 5)$ \\
1983 & $4 \cdot 9(20 \cdot 3)$ \\
1984 & $4 \cdot 0(13 \cdot 6)$ \\
1985 & $3 \cdot 8(2 \cdot 6)$ \\
1986 & $2 \cdot 9(3 \cdot 9)$ \\
1987 & $4 \cdot 6(4 \cdot 5)$ \\
1988 & $3 \cdot 5(4 \cdot 8)$ \\
\hline
\end{tabular}

${ }^{\star}$ For two patients.

already been made by non-invasive techniques, which are independently predictive. "Nevertheless, until the coronary anatomy is known confident assessment of the risk of coronary events cannot be made. Six of our patients died 28-180 days after referral for investigation. Emergency referrals were not included in this figure and the patients were thought to be stable. The much shorter waiting time in the private sector was associated with no deaths. It is disturbing to note that all but one of the nine patients who died awaiting surgery after an interval of up to 400 days had disease of three vessels and impaired left ventricular function, both known to carry a poor prognosis and to benefit from early surgery. ${ }^{2}$ Finally, $74(19 \cdot 5 \%)$ of all our patients on the NHS waiting list waited longer than one

TABLE V-Mean $(S D)$ number of days from angiography to revascularisation for NHS and private patients with coronary artery disease with stable symptoms

\begin{tabular}{|c|c|c|c|c|c|}
\hline $\begin{array}{l}\text { Year of } \\
\text { referral }\end{array}$ & NHS patients & Private patients & Mean (SD) difference & $\begin{array}{l}\text { Degrees of } \\
\text { freedom }\end{array}$ & $95 \%$ Confidence interval \\
\hline 1979 & $217 \cdot 5(276 \cdot 3)$ & $28 \cdot 0(0)$ & $189 \cdot 5(293 \cdot 1)$ & 7 & $882 \cdot 2$ to $-504 \cdot 2$ \\
\hline 1980 & $260.0(275 \cdot 4)$ & $22 \cdot 3(12 \cdot 6)$ & $237 \cdot 7(274 \cdot 4)$ & 11 & $841 \cdot 2$ to $-366 \cdot 8$ \\
\hline 1981 & $329 \cdot 3(359 \cdot 1)$ & $27 \cdot 6(30 \cdot 7)$ & $301 \cdot 7(137 \cdot 7)$ & 17 & 591.9 to 10.9 \\
\hline 1982 & $217 \cdot 4(118 \cdot 6)$ & $30 \cdot 0(19 \cdot 0)$ & $187 \cdot 4(66 \cdot 8)$ & 54 & $321 \cdot 3$ to $53 \cdot 5$ \\
\hline 1983 & $138 \cdot 7(121 \cdot 8)$ & $33.6(26.5)$ & $105 \cdot 1(41 \cdot 5)$ & 47 & $188 \cdot 6$ to $21 \cdot 6$ \\
\hline 1984 & $107.9(82.9)$ & $12 \cdot 3(17 \cdot 2)$ & $95 \cdot 6(39 \cdot 9)$ & 28 & 177.3 to 13.9 \\
\hline 1985 & $88 \cdot 3(100 \cdot 8)$ & $24 \cdot 0(13 \cdot 9)$ & $64 \cdot 3(28 \cdot 8)$ & 29 & $123 \cdot 2$ to $5 \cdot 4$ \\
\hline 1986 & $125 \cdot 8(151 \cdot 8)$ & $23 \cdot 4(29 \cdot 1)$ & $102 \cdot 4(43 \cdot 8)$ & 56 & $190 \cdot 1$ to 14.7 \\
\hline 1987 & $316 \cdot 1(355 \cdot 5)^{\star}$ & $14 \cdot 1(12 \cdot 3)$ & $302 \cdot 0(79 \cdot 5)$ & 82 & $460 \cdot 1$ to 143.9 \\
\hline 1988 & $305.9(164 \cdot 4)^{\star}$ & $13 \cdot 6(19 \cdot 7)$ & $292 \cdot 3(41 \cdot 4)$ & 86 & $373 \cdot 7$ to $209 \cdot 1$ \\
\hline
\end{tabular}

${ }^{\star}$ Data are biased as four patients referred in 1987 and 10 referred in 1988 were not operated on until 1 September 1990.

year after investigation and needed re-examination before surgery, further prolonging the waiting time and cost of the investigation or treatment module.

The private sector has apparently been able to absorb the increased workload while the NHS has shown an adverse trend over the past three years despite increased surgical and angiographic activity. Other data from our unit suggest a national need for coronary artery bypass grafting in 1988 to have been between 400 and 600 procedures/million population/ year, ${ }^{12}$ although the Department of Health has recommended a target of 300 procedures/million population/year for $1990 .^{6}$ The population of South West Thames region is about 2.96 million, and the regional need would therefore be about 2000 coronary angiograms and 1200 surgical or revascularisation procedures/year. In 1988 the regional centre performed 2026 cardiac catheter procedures of all forms and 542 coronary bypass operations on patients from within and outside the region. The region also includes a cardiac catheterisation facility at the Mayday Hospital, where a further 350 procedures were performed (S Joseph, personal communication) and some patients are referred to the Royal Brompton and National Heart Hospital. Activity in the private sector might mitigate the above projections by some $10-15 \%$.

At present the number of coronary artery bypass graft procedures performed in the United Kingdom is probably half that required. ${ }^{612}$ Even allowing for some improvement in efficiency, it is clear that a major investment in both capital and resource terms will be needed if a large number of uninsured patients are not to be disadvantaged each year in terms of quality of life and risk of cardiovascular mishap. Furthermore, it is not clear how existing budgets, inadequate as they are for cardiovascular services, will be devolved on to districts under the forthcoming white paper proposals. ${ }^{13}$ Some, such as the North West Surrey district, with well developed cardiological services will lose out if the existing budget is to be applied more or less evenly across the region to reflect the incidence of coronary artery disease. If the distribution were to be skewed to reflect current levels of activity patients in less well developed districts would be disadvantaged.

In conclusion, our data have shown that the South West Thames regional cardiac centre is not able to provide an adequate service for routine invasive cardiological assessment and revascularisation. Despite increased investigative and surgical activity there is no evidence of the situation coming under control, and without additional funding it is not easy to see how it will do so. There seems to be a two tier service, with rapid and certain progress being restricted to those prepared to pay or who are privately insured.

We thank Dr S Gallivan, University College London, for statistical advice.

1 Office of Population Censuses and Survevs. 1986 Mortality statistics: cause. London: HMSO, 1987. (Series DH5, No 12.)

2 Myers WO, Genk BJ, Fisher LD, et al. Medical versus early surgical therapy in patients with triple vessel disease and mild angina. A CASS registry study of patients with triple vessel disease and mild angina
survival. Am f Thoracic Surg 1987;44:471-86.

3 Califf RM, Harell FE, Lee KL, et al. The evolution of medical and surgical therapy for coronary artery disease. A fifteen year perspective. $\mathcal{F} A M A$ 1989;97:78-85.

4 Caine N, Harrison SCW, Sharples ID, et al. Prospective study of quality of life before and after coronary bypass grafting. BMF 1991;302:511-6.

5 Vamaurkas E. Survival, myocardial infarction and employment status in a prospective randomized study of coronary bypass. Circulation 1985;72: 90-101.

6 National Audit Office. Coronary heart disease. London: HMSO, 1989

7 Cripps T, Dennis MS, Joy M. The need for invasive cardiological assessment and operation: viewpoint of a district general hospital. Br Heart 1986;55:488-93.

8 Armitage P, Berry G. Statistical methods in medical research. 2nd ed. Oxford: Blackwell, 1987

9 Gardner MJ, Altman DG. Statistics with confidence. London: BMF, 1990.

10 Consensus Development Conference. Coronary artery bypass surgery grafting. BMf 1984:289:1527-9.

11 Weiner DA, Ryan TJ, McCabe CH, et al. Prognostic importance of clinical profile and exercise test in medically treated patients with coronary artery disease. I Am Coll Cardiol 1984;3:772-9.

12 MacRae CM, Marber $M$, Keywood C, Joy $M$. The need for invasive investigation and revascularisation of the myocardium in South West Thames region. $\mathrm{Br}$ Hearl $\mathcal{f}$ (in press)

3 Secretaries of State for Health, Wales, Northern Ireland, and Scotland. Working for patients. London: HMSO, 1989. (Cmnd 555.)

(Accepted 10 April 1991)

Update box for Oxford Handbook of Clinical Medicine (2nd ed), p 328

\section{Disposable end tidal carbon dioxide detectors}

Disposable end tidal carbon dioxide detectors use a chemical pH indicator (metacresol) to detect the presence of carbon dioxide in expired gases. The colour varies respectively from mauve to yellow with inspiration and expiration. Mauve indicates a carbon dioxide concentration of $<0.5 \%$, tan one of about $0.5-2 \%$, and yellow one of about $2-5 \%$. The devices' cyclic colour change with each breath may be used to distinguish oesophageal from tracheal intubation-except that contamination with gastric fluid produces a permanent orange colour that may falsely reassure the unwary. Also, when a patient is being resuscitated with lignocaine or adrenaline given through an endotracheal tube (p 724) a permanent yellow colour occurs. The device works for about two hours before replenishment is needed. - J M LONGMORE

\section{Principal sources}

Higgins D, Haves M, Denman W, Wilkinson DJ. Effectiveness of using end tidal carbon dioxide concentration to monitor cardiopulmonary resuscitation. $B M F$ f 1990;300:581.

Muir JD, Randalls PB, Smith GB. End tidal carbon dioxide detector for monitoring cardiopulmonary resuscitation. BMF 1990;301:41-2.

Hayes M, Yau EHS, Higgins D, Denman W, Wilkinson DJ. End tidal carbon dioxide detector for monitoring cardiopulmonary resuscitation. BMF 1990;301:42.

Anyone may submit an update box; all boxes are peer reviewed. 